\title{
The design of the fan mold based on Pro/E
}

\author{
Jun $\mathrm{Ji}^{1}$, Fei-Fei Xing ${ }^{2}$, Jun $\mathrm{Du}^{1}$, Hao Li ${ }^{1}$, Heng-Ju Chen ${ }^{1}$ \\ ${ }^{1}$ Beijing Polytechnic, Beijing 100176 China \\ ${ }^{2}$ BMEI CO., LTD., Beijing 100027, China
}

\section{Keyword: Pro/E; Fan Cover Mold; Fan Blade Mold}

Abstract: This paper mainly introduces the mold design using Pro/E the fan cover and fan blades. The main contents include: the basic knowledge of Pro/E, fan mold design of Pro/E function command. The whole process of mold design with Pro/E, introduces the method of mold.

\section{Introduction}

Pro/ENGINEER software provides the most comprehensive and closely integrated product development environment: PTC series software includes a number of features in the industrial design and mechanical design, the large assembly management, functional simulation, manufacturing, product data management and so on[1-3]. It has been widely used in electronics mechanical, aerospace, automotive, mold, household appliances and other industries; especially the injection molding. So the design and manufacture of plastic products are mostly applied to Pro/E[4-5].

\section{The detailed design of fan blade}

\section{Load reference mode}

1) Set working directory

2) Open file

Click the file, open the fan_mold_mfg document, the fan model and the work-piece model is loaded to the drawing.

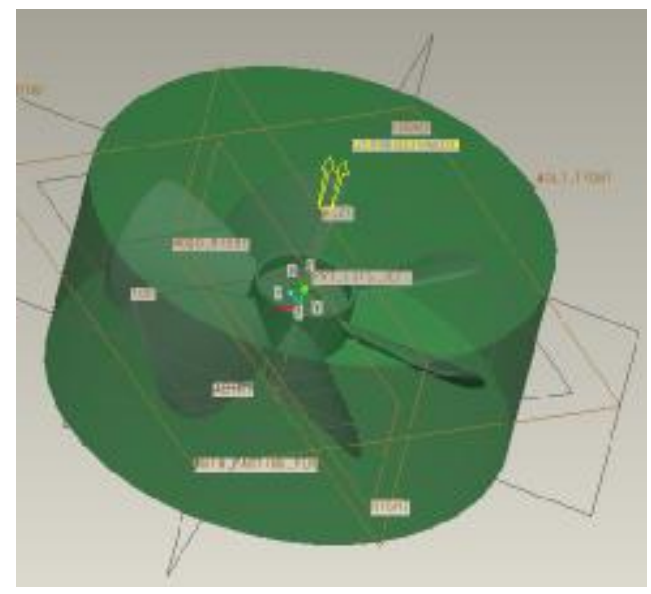

Fig. 1 position of fan in the design environment of "die cavity"

\section{Create parting surface}

1) Create pattern of parting surface 
2) Enter screen-shot drawing mode

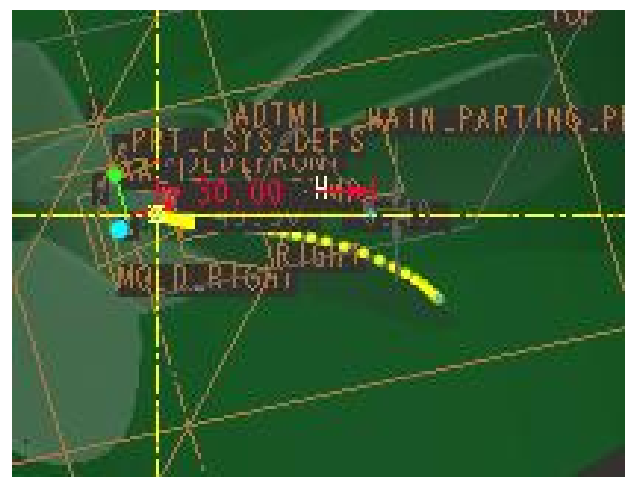

Fig. 2 section area of grass

2. Picture merge, as shown in Figure 3.

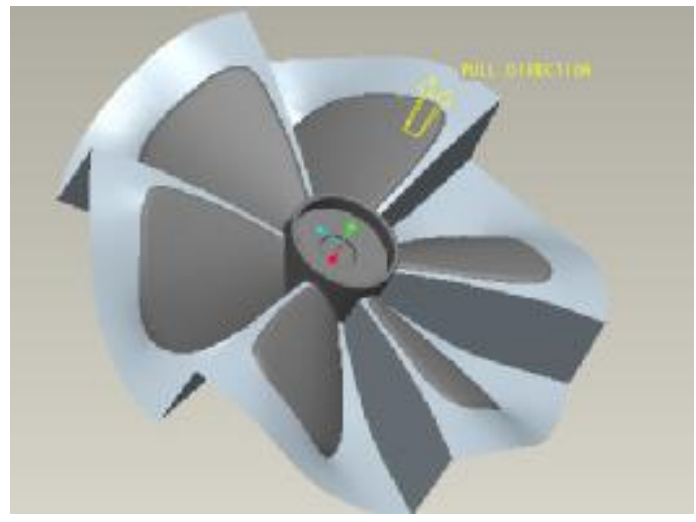

Fig. 3 combined surface

\section{Design of molding parts}

1) Click the toolbar to create a volume block.

2) Click the "die components" button in the pop-up "create the mold element" dialog box, click "select all volume blocks", select all objects, click "ok".

3 ) In the mold element cavity .prt model tree right-click pop-up window procedure just created, the cavity model, as shown in Figure 4. The same method can be used to open the core.prt mold element model. As shown in Figure 5.

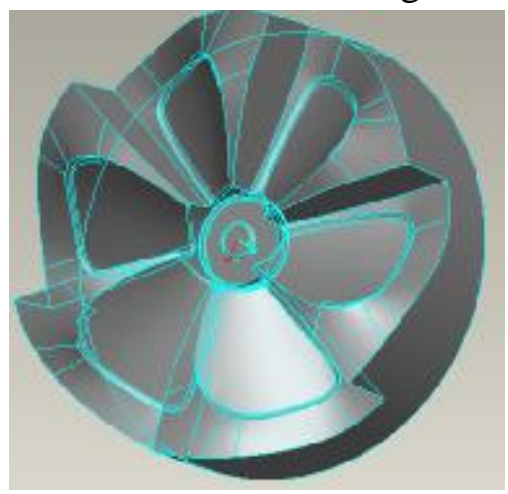

Fig. 4 cavity element

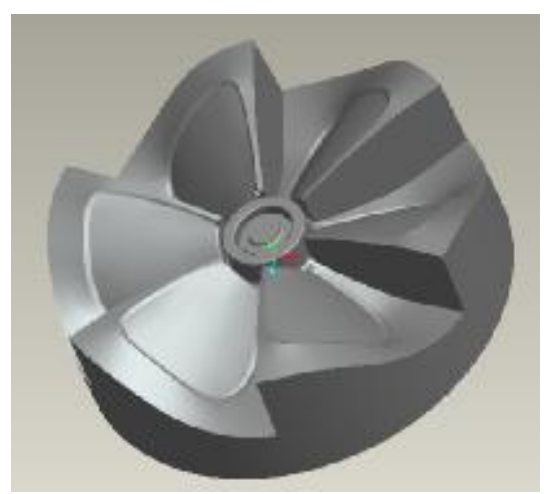

Fig. 5 core elements

\section{Design of gating system}

1) In order to click the "mold" and "features" - "cavity components" - "entities" - "cut material" - 
"rotation" - "entities" - "complete".

2) "Rotate" control panel pop up, in the "position" on the definition of grass on the slide panel, select MOLD_FRONT for the grass drawing plane.

3) Click the button on the control panel to complete the creation of the feature. As shown in Figure 6.

4) Effect drawing of mold expansion. As shown in Figure 7.

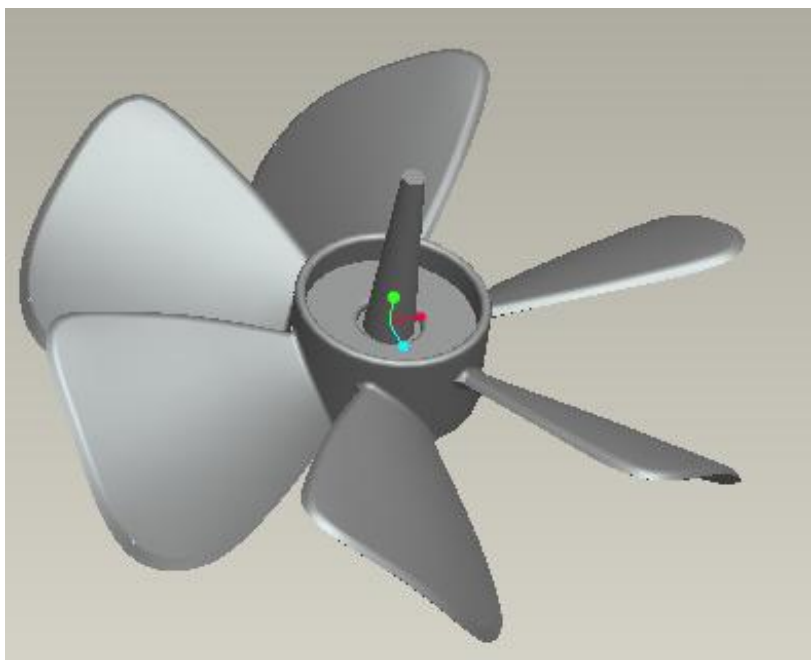

Fig. 6 mold parts

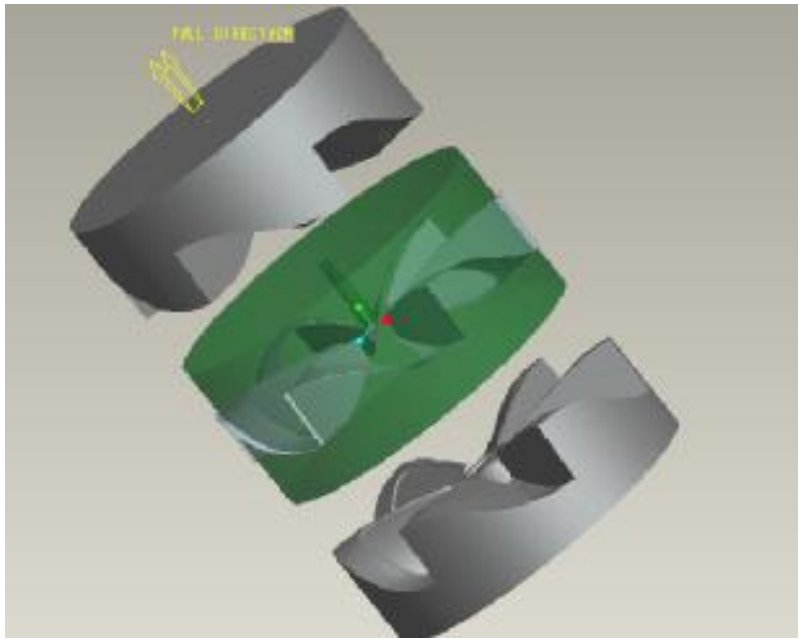

Fig. 7 Effect of mold expansion

\section{Summary}

This paper mainly introduces the design of fan cover and fan blade mold using Pro/E. The main contents include: the basic knowledge of Pro/E, fan mold design Pro/E function commands. The whole process of mold design with Pro/E, introduces the method of mold.

\section{References}

1 Liming Xiao.Pro/ENGINEER wildfire version of part design complete analysis of Beijing: China Railway Publishing House 2010

2 Yougang Zhan.Pro/ENGINEER Chinese wild fire version 5 curved surface 
design example analysis Beijing: Mechanical Industry Press 2010

3 Qian Xiao.Wildfire3.0.Pro/ENGINEER Chinese version of practical guide Beijing: China Electric Power Press 2008

4 Qian Xiao,Yingxin Yang.Wildfire3.0 Pro/ENGINEER case listed in Beijing: China Electric Power Press, 2008

5 Qian Xiao,Huilan Zhou.Wildfire3.0 Pro/ENGINEER Chinese version of mold design and nc machining Beijing: China Electric Power Press 2008 